\title{
The Effect of 40 Days Static Stretching After Prayers on Flexibility Among Elderly Muslim Men
}

\author{
Mazlan Ismail ${ }^{1}$ \\ ${ }^{1}$ Faculty of Sports Science and Recreation, Universiti Teknologi MARA, Shah Alam, Selangor, Malaysia \\ Correspondence: Mazlan Ismail. E-mail: docmalanuitm@gmail.com
}

Received: May 8, 2020

Accepted: July 1, 2020

Online Published: October 31, 2020

doi:10.5539/ass.v16n11p1

URL: https://doi.org/10.5539/ass.v16n11p1

\begin{abstract}
This study was conducted to determine the effect of 5 times static stretching for 40 days on flexibility. A pre-experimental research design was used and the participants comprising 20 sedentary male aged $60-64$ years of different weight and height participated in this study. They were engaged in 10 minutes of stretching for five times a day (after prayer) for 40 days of interventions. All participants completed the flexibility test before and after the intervention. The results showed that the participants had increased in inches in terms of flexibility after 40 days of intervention. The present study recommends static stretching after prayers (salat) as another approach for elderly people to prepare themselves before and during performing hajj or umrah. Future research may investigate its relationship with the psychological states of the participants and other health related fitness components.
\end{abstract}

Keywords: static stretching, prayers, flexibility, elderly

\section{Introduction}

A person is considered old upon reaching the age of 65 or above. They are classed into three categories which are 65 to 74 years (young elderly), 75 to 84 years (old elderly), and above 85 years (older elderly) (Papila, Olds, \& Feldman, 2006). Hence, the likelihood of elderly people facing a decrease in their postural stability is very high (Nejc, Loefler, Cvecka, Sedliak, \& Kern, 2013). As revealed by Coriolano Appell, Perez, Maio Nascimento, and Appell Coriolano (2012), the functional capacities of every aging person.

The term physical activity may be defined in several ways. Physical activity includes all movements associated with everyday life (e.g., work, routine activities, exercise activities, and recreational activities (Miller, 2002). Generally, older adults are in retirement or that their work responsibilities require little physical activity. For this reason, it is important that their lifestyle incorporates recreational activities, exercise, or other activities that require physical exertion. Duarte and Appell (2005) suggest that a person should maintain an active lifestyle because the process of aging occurs varyingly for every individual.

Though it is accepted that regular physical activity can benefit the elderly regardless for all older individuals regardless of their physical health, it is not advisable, however, to enforce exercise or activity guidelines for all older adults. Although a sedentary lifestyle is often directly related to chronic diseases associated with aging, the activity level of many individuals' declines with age even for those with no chronic disease. Past researchers have highlighted the effectiveness of physical activity for elderly people particularly on their physical, social, and psychological well-being (Mechling \& Netz, 2009). According to Benjuya, Melzer, and Kaplanski (2004), a person's ability to balance can be monitored by asking the person to stay in an upright posture while performing static and dynamic tasks. If their body balance is poor, their daily activity will be disrupted (Chou, Hwang, \& $\mathrm{Wu}, 2012$ ) hence, proper intervention needs to be introduced regularly to elderly so as to improve their quality of life and reduce their risk of falling. Past researchers have also found that strength training and coordinative exercise can benefit the elderly by controlling their postural stability (Skelton, 2001). Nonetheless, there is insufficient literature on flexibility training related particularly to elderly people (Frankel, Bean \& Frontera, 2006). Barret and Smerdely (2002) have reported that apart from resistance training, flexibility training improves balance performance other than resistance training.

Muslims from all over the world congregate to Makkah for the annual hajj pilgrimage which includes three days of walking on various religious sites. The spiritual journey can be as taxing on the body, as doing on extended 
bout of physical activity or a hiking trip. Thus, there is a need for research could offer suggestion to help that avoid tight muscle or pain which could allow elderly pilgrimages' to walk more efficiently for long periods of time. Indeed, the role of stretching after prayers for Muslims has never been explored by researchers. Stretching should be the ideal intervention for elderly people to apply as a home-based exercise program, in particular when performing hajj or umrah. Thus, the objective of this study is to investigate the effect of 5 times static stretching for 40 days on flexibility among a group of elderly men.

\section{Methods}

\subsection{Participants}

The participants in this study comprised twenty sedentary male aged $60-64$ years, $(M=62.05, S D=1.50)$ of different weight and height $(M=78.95, S D=9.28),(M=1.69, S D=.02)$. They were recruited from a special training program conducted by Healthy Generation Malaysia.

The participants engaged in 10 minutes of static stretching as recommended by the American College of Sports Medicine (2014), five times per day equivalent to the number of compulsory prayers for Muslim for 40 days equivalent to the numbers of days performing hajj. This program was conducted by a certified sports science instructor. To participate in this study, they were required to provide a written inform consent. Static stretching consists of 10 steps of static stretching with 60 seconds per step and followed by breathing techniques (see Figure 1).

\begin{tabular}{l} 
Hamstrings stretch \\
Sescription \\
$\begin{array}{l}\text { Seated with both legs extended. Put the hands on the ankles or toes. Ensure } \\
\text { neutral spine while flexing forward at hip, keeping extended leg straight. } \\
\text { Hold the stretch for } 30 \text { seconds and then repeat the same stretch for a } \\
\text { second time. }\end{array}$ \\
Hamstrings and groin stretch \\
$\begin{array}{l}\text { Sit with one leg extended and other knee bent out to the side. Ensure neutral } \\
\text { spine while flexing forward at hip, keeping extended leg straight. Hold the } \\
\text { stretch for } 30 \text { seconds and then repeat the same stretch on the other leg. }\end{array}$ \\
$\begin{array}{l}\text { Seated with } 1 \text { leg extended to front and foot sole of bent leg against inner } \\
\text { thigh, rotate upper torso outwards to side of bent leg. Maintain up right } \\
\text { posture without rounding up back leaning backwards. Hold the stretch for } \\
\text { 30 seconds and then repeat the same stretch on the other side }\end{array}$ \\
$\begin{array}{l}\text { Sit tall with knees bent outward and soles of feet against each other. Place } \\
\text { hands on ankles and depress elbow against back of knees while flexing } \\
\text { forward from hip. Hold the stretch for 30 seconds and then repeat the same } \\
\text { stretch for a second time. }\end{array}$ \\
\hline
\end{tabular}



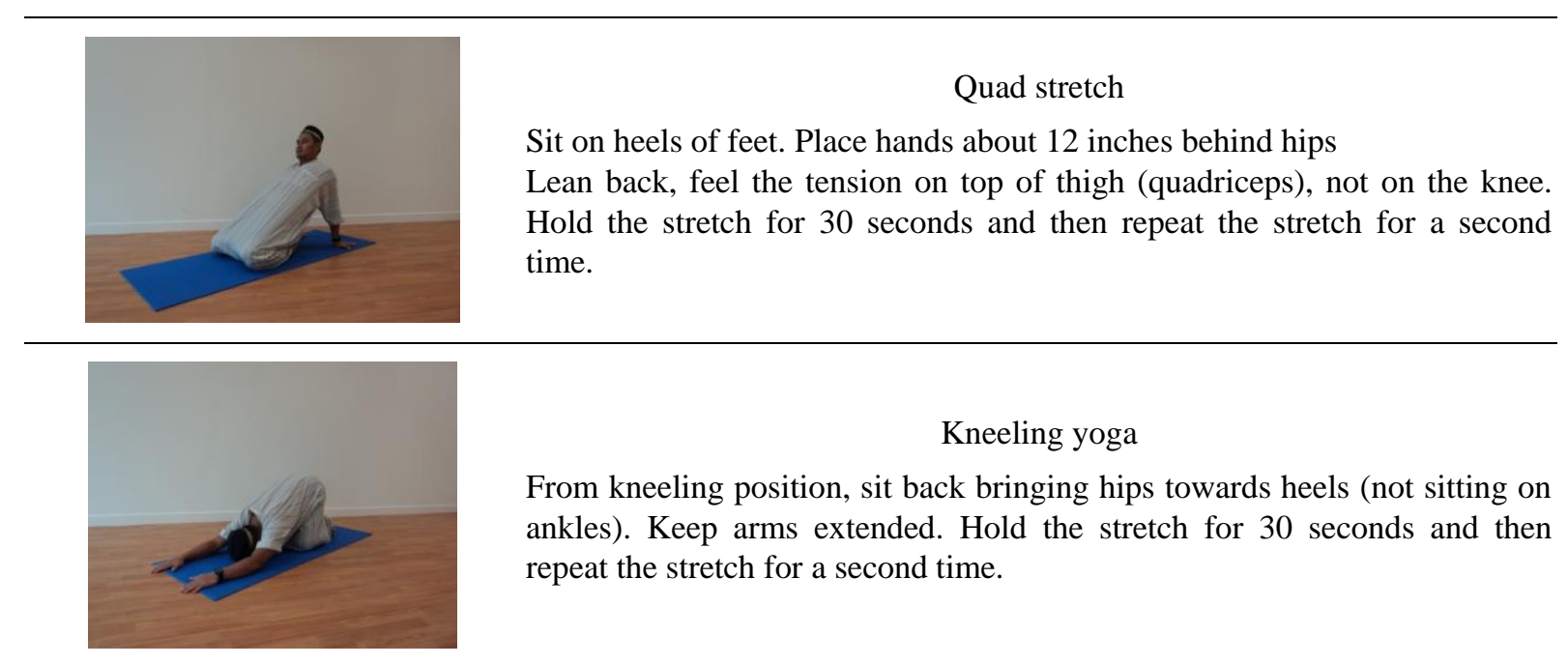

\section{Kneeling yoga}

From kneeling position, sit back bringing hips towards heels (not sitting on ankles). Keep arms extended. Hold the stretch for 30 seconds and then repeat the stretch for a second time.

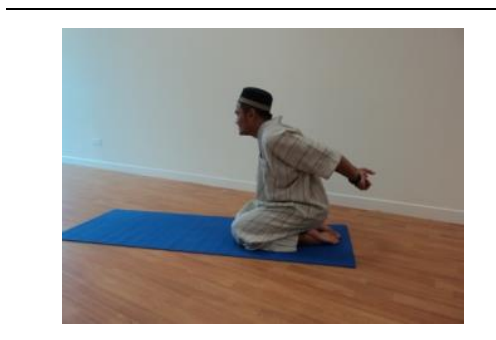

Chest and shoulder stretches

In a kneeling position, slowly interlace the fingers and raise your arms behind you. Go as far as you can until you feel a good stretch in the shoulders. Hold the stretch for 30 seconds and then repeat the stretch for a second time.

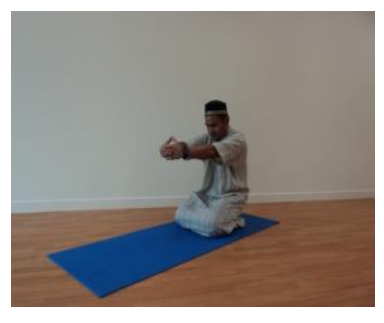

\section{Upper back stretch}

In a kneeling position, stretch the arms straight out and rotate the hands so that the palms face away from each other. Push the arms forward. Hold the stretch for 30 seconds and then repeat the stretch for a second time.

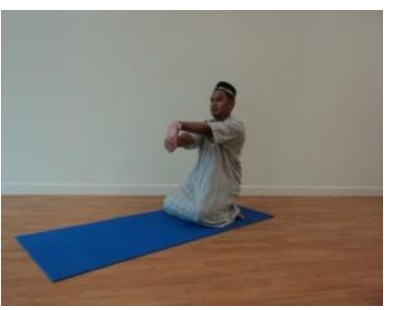

\section{Forearm stretch}

In a kneeling position, stretch the right arm out and turn the hand down so that the fingers point towards the floor. Use the left hand to gently pull the fingers towards you, feeling a stretch in the forearm. Hold the stretch for 30 seconds and then repeat on the other side.

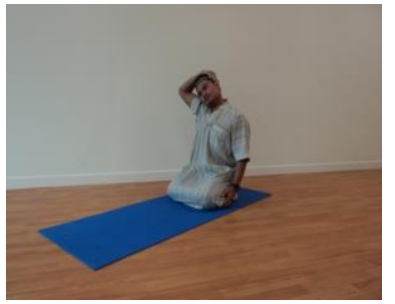

Neck stretch

In a kneeling position, tilt your head to the left and put your hand on your ear. Do not push your head down. Feeling a stretch down the right side of the neck and shoulder. Hold the stretch for 30 seconds and then repeat on the other side.

Figure 1. Ten Steps of Static Stretching

The present study only selected one test (trunk/leg flexibility) to evaluate the ability of elderly people to carry on certain activities. The reliability of the test was .98 (Osness et al., 1996).

Trunk / leg flexibility: Sit and reach. This test procedure is similar to the sit and reach test item included in the YMCA Physical Fitness Test. A yardstick is taped to the floor with a perpendicular line over the 25-inch mark. The test performer, with shoes removed, sits with the legs extended flat on the floor and the heels at the 25 -inch 
mark. The yardstick should be between the legs, with the (0) point toward the performer. With the feet spread about 12 inches apart and one hand placed directly on top of the other, the performer slowly reaches forward, sliding the hands along the yardstick as far as possible. The performer must hold the final position for at least 2 seconds. The test administrator should place a hand on top of one of the performer's knees to ensure that the knees are not raised during the test. Two practice trials are permitted, and the better of two test trials is recorded. The score is recorded to the nearest $1 / 2$ inch.

\subsection{Procedure}

A pre-experimental design study was conducted to identify the effects of 10 minutes static stretching on flexibility. The present study used the trunk/leg flexibility to evaluate the ability of elderly men to carry on certain activities. Stretching was done 5 times per day for 40 days during the training program. At the initial meeting, the participants underwent a health screening test before engaging in the program. Based on the medical clearance form recorded, all participants were free from any injuries and health problems. As recommended by the previous study, they had only performed some physical activity for less than one hour per week for at least a year prior to the intervention program (Ashira, Ratanavadee, Alongkot, \& Katarina, 2010). Additionally, a medical assistant was assigned to monitor during the entire intervention session. Next, all participants were asked to complete 5 times per day of stretching program conducted by the certified instructor. Overall, the static stretching approximately lasted 10 minutes per session (Devries, 1962).

\section{Results and Discussion}

The preliminary assumption was normally distributed and a paired - samples t-test was conducted to evaluate the effects of 10 minutes of 5 times static stretching per day for 40 days on flexibility test among elderly men. Table 1 shows that there is a statistically significant improvement in inches of flexibility level from pre-test $(M=13.35$, $S D=4.19)$ to post test $(M=18.00, S D=3.71), t(19)=-14.56, p<.001$ (two tailed). The mean decrease in flexibility level was -4.65 with a $95 \%$ confidence interval ranging from -5.32 to -3.98 . The eta squared statistic (1.0) indicates a large effect size.

Table 1. Comparison of flexibility Level for pre-test and post-test

\begin{tabular}{|c|c|c|c|c|c|c|c|}
\hline \multirow[t]{2}{*}{ Measure } & \multicolumn{2}{|c|}{ Pre test } & \multicolumn{2}{|c|}{ Post test } & \multirow[b]{2}{*}{$t$} & \multirow[b]{2}{*}{$p$} & \multirow[b]{2}{*}{ ES } \\
\hline & $\mathrm{M}$ & SD & $\mathrm{M}$ & $\mathrm{SD}$ & & & \\
\hline Flexibility & 13.35 & 4.19 & 18.00 & 3.71 & -14.59 & $<.001$ & 1.0 \\
\hline
\end{tabular}

Note. ES $=$ Eta Squares

The static stretching performed for only 10 minutes 5 times per day for 40 days shows an improvement in inches of flexibility among elderly men aged (60 - 64 years). The most interesting findings in this pilot study is that static stretching when altered into a 10 steps for 10 minutes for 5 times after prayers per day was sufficient to increase inches in flexibility in sedentary older men. Additionally, this result supports other researchers who have experienced with stationary stretching (Rani \& Mohanty, 2015; Gallon et al., 2011) and other methods of training (Long, Jackson, \& Laubach, 2013; Shubert, McCulloch, Hartman, \& Giuliani, 2010; Barrett \& Smerdely, 2002). The improvement found in the present study can be attributed to the 10 minutes of static stretching as supported by the previous studies (Gallon et al., 2011; Ferber, Ostering, \& Gravelle, 2002). The findings of the study are considered the first to determine the effects of static stretching after prayers for 40 days on elderly people.

The limitations found in this study are when the pre-experimental and only one group study design is weaker than true-experimental designs in terms of control. Therefore, the true experimental designs are recommended for future studies (Baumgartner \& Hensley, 2006). Furthermore, it is recommended that the routines and activities of hajj, as well as the different components of fitness like cardiovascular and muscular endurances are included in future studies. Further research is also needed to determine the relative effectiveness of fitness components in the psychological and well - being of elderly people (Netz, Wu, Becker, \& Tenenbaum, 2005; Arent, Landers, \& Etnier, 2000).

\section{References}

American College of Sports Medicine. (2014). ACSM's guidelines for exercise testing and prescription (9th ed.). Philadelphia (PA): Wolters Kluwer/Lippincott Williams \& Wilkins. 
Arent, S. M., Landers, D. M., \& Etnier, J. L. (2000). The effects of exercise on mood in older adults: A Meta analytic review. Journal of Ageing and Physical Activity, 8(4), 407-430. https://doi.org/10.1123/japa.8.4.407

Ashira, H., Ratanavadee, N., Alongkot, E., \& Katarina, T. B. (2010). Effect of once a week endurance exercise on fitness status in sedentary subjects. Journal of the Medical Association of Thailand, 93(9), 1070-1074.

Barrett, C., \& Smerdely, P. (2002). A comparison of community - based resistance exercise and flexibility exercise for seniors. Australian Journal of Physiotherapy, 48(3), 215-219. https://doi.org/10.1016/S0004-9514(14)60226-9

Baumgartner, T. A., \& Hensley, L. D. (2006). Conducting and Reading Research in Health and Human Performance. McGraw Hill: New York.

Benjuva, N., Melzer, L., \& Kaplanski, J. (2004). Aging - induced shifts from a reliance on sensory input to muscle contraction during balanced standing. The Journals of Gerontology. Series, a Biological Sciences and Medical Sciences, 59(2), 166.

Chou, C. H., Hwang, C. L., \& Wu, Y. T. (2012). Effect of exercise on physical function, daily living activities, and quality of life in the frail older adults a meta-analysis. Archives Physical Medicine Rehabilitation, 93(2), 237-244. https://doi.org/10.1016/j.apmr.2011.08.042

Coriolano Appell, I. P., Perez, V. R., Maio Nascimento, M., \& Appell, H. J. (2012). The Pilates method to improve body balance in the elderly. Archives of Exercise in Health and Disease, 3(3), 188-193. https://doi.org/10.5628/aehd.v3.i3.126

Devries, H. A. (1962). Evaluation of static stretching procedures for improvement of flexibility. Research Qualitative, 33(2), 222-229. https://doi.org/10.1080/10671188.1962.10613194

Duarte, J. A., \& Appell, H. J. (2005). Physical activity for longevity - does the dosage make the poison. European Review Aging Physical Activity, 2, 6-12.

Ferber, R., Ostering, L., \& Gravelle, D. (2002). Effect of PNF stretch techniques on knee flexor muscle EMG activity in older adults. Journal Electromyograms Kinesiology, 12(5), 391-397. https://doi.org/10.1016/s1050-6411(02)00047-0

Frankel, J. E., Bean, J. F., \& Frontera, W. R. (2006). Exercise in elderly: research and clinical practice. Clinics in Geriatric Medicine, 22(2), 239-256. https://doi.org/10.1016/j.cger.2005.12.002

Gallon, D., Rodacki, A. L. F., Hernandez, S. G., Drabovski, B., Outi, T., Bittencourt, L. R., \& Gomes, A. R. S. (2011). The effects of stretching on the flexibility, muscle performance and functionality of institutionalized older women. Brazilian Journal Medicine Biological Research, 44(3), 229-235. https://doi.org/10.1590/S0100-879X2011007500012

Long, L., Jackson, K., \& Laubach, L. (2013). A home-based exercise program for the foot and ankle to improve balance, muscle performance, and flexibility in community dwelling older adults a pilot study. International Journal of Physical Medicine and Rehabilitation, 1(3), 1-6. https://doi.org/10.4172/2329-9096.1000120

Mechling, H., \& Netz, Y. (2009). Aging and inactivity - capitalizing on the protective effect of planned physical activity in old age. European Review Aging Physical Activity, 6(2), 89-97. https://doi.org/10.1007/s11556-009-0052-y

Miller, D. K. (2002). Measurement by the Physical Educator Why and How (4th ed.). New York: McGraw-Hill.

Nejc, S., Loefler, S., Cvecka, J., Sedliak, M., \& Kern, H. (2013). Strength training in elderly people improves static balance a randomized controlled trial. European Journal Translational Myology, 23(3), 85-89. https://doi.org/10.4081/ejtm.2013.1777

Netz, Y., Wu, M. J., Becker, B. J., \& Tenenbaum, G. (2005). Physical activity and psychological well-being in advanced age: A meta-analysis of intervention studies. Psychological and Ageing, 20(2), 272-284. https://doi.org/10.1037/0882-7974.20.2.272

Osness, W. H. et al. (1996). Functional Fitness Assessments for Adults Over 60 Years (2nd ed.). Dubuque, iowa: Kendall/Hunt Publishing.

Papilla, D. E., Olds, S. W., \& Feldman, R. D. (2006). Desenvolvimentao Humano (8th ed.). Porto Alegre: Artmed.

Rani, B., \& Mohanty, P. P. (2015). A comparison between two active stretching techniques on hamstring flexibility in asymptomatic individuals. IOSR Journal of Dental and Medical Sciences, 14(4), 12-16. 
https://doi.org/10.9790/0853-144101216

Shubert, T. E., McCulloch, K., Hartman, M., \& Giuliani, C. A. (2010). The effect of an exercise - based balance intervention on physical and cognitive performance for older adults: A pilot study. Journal of Geriatric Physical Therapy, 33(4), 157-164.

Skelton, D. A. (2001). Effects of physical activity on postural stability. Age Ageing, 30(4), 33-39. https://doi.org/10.1093/ageing/30.suppl_4.33

\section{Copyrights}

Copyright for this article is retained by the author(s), with first publication rights granted to the journal.

This is an open-access article distributed under the terms and conditions of the Creative Commons Attribution license (http://creativecommons.org/licenses/by/4.0/). 